\title{
Selektywne regeneracyjne napawanie plazmowe warstw Ni-WC na tytanowe topatki sprężarki silnika lotniczego
}

\section{Selective regeneration of Ni-WC layers over titanium-made compressor blades of aircraft engines by plasma surfacing}

\section{Streszczenie}

W artykule przedstawiono opracowaną metodę wraz z wynikami badań napawania mikroplazmowego kompozytowych warstw Ni-WC na półki łopatek sprężarki ze stopu tytanu. Analizowano strukturę napoin, ze szczególnym uwzględnieniem rozkładu pierwiastków dla okolicy linii wtopienia warstwy kompozytowej w podłoże oraz granicy międzyfazowej osnowa warstwy - węglik wolframu. Wyniki wskazują na intensywne oddziaływanie cieczy z fazą stałą: podłożem i cząstkami węglika podczas procesu napawania.

\section{Wstęp}

Stopy tytanu ze względu na swoje unikalne właściwości znajdują zastosowanie w wybranych konstrukcjach, w tym w silnikach samolotów odrzutowych. Wytwarzane są z nich $\mathrm{m}$. in. łopatki sprężarek. Przy zachowaniu wysokich właściwości mechanicznych słabszą stroną części wykonanych ze stopów tytanu technologiami odlewania lub przeróbki plastycznej jest niewystarczająca odporność na zużycie ścierne i zmienne naciski.

Jednoprzepływowa sprężarka osiowa jest największym z zespołów silnika odrzutowego, gdzie jest osadzonych 14 stopni łopatek na jednym wale. Łopatki stopnia zerowego są największe (rys. 1). Aby usunąć

Dr inż. Jerzy Jakubowski, prof. dr hab. Inż. Jacek Senkara - Politechnika Warszawska, mgr inż. Piotr Wysocki - Wojskowe Zakłady Lotnicze $\mathrm{Nr} 4$ w Warszawie.

\section{Abstract}

The developed method along with results of microplasma surfacing of $\mathrm{Ni}-\mathrm{WC}$ composite layers onto titanium alloy compressor blades are presented in the article. Structure of overlays were analysed with particular interest in elements distribution close to the fusion line of composite layer - substrate as well as in the matrix tungsten carbide interface. The results point out an intensive interaction between the melt and the solid phase (substrate and carbide particles) in the course of surfacing process.

lub zmniejszyć naprężenia powstające w czasie pracy w wyniku wibracji, na części roboczej pióra usytuowane są miejsca podparcia nazywane półkami. Półki poszczególnych łopatek są spasowane wciskowo z sąsiednimi, tworząc tzw. bandaż, Takie rozwiązanie konstrukcyjne pozwala na istotną redukcję drgań łopatek oraz zmianę charakterystyki wibracyjnej całego zespołu.

Powierzchnia styku półek bandaża jest newralgicznym miejscem konstrukcji, ze względu na charakter pracy elementu. Pod wpływem dużego momentu obrotowego następuje odkształcanie łopatek, któremu

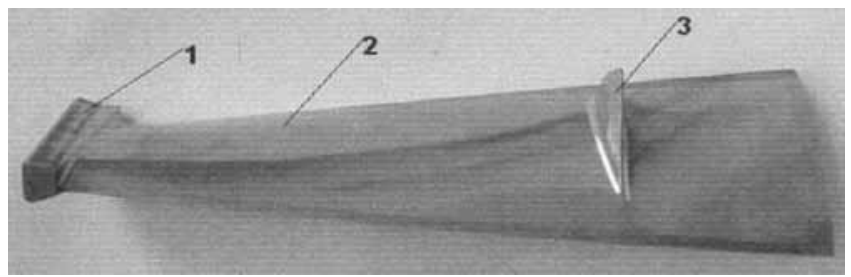

Rys. 1. Tytanowa łopatka turbiny sprężarki stopnia zerowego: 1 - stopa do mocowania łopatki w zamku tarczy; 2 - pióro; 3 - półka bandaża

Fig. 1. Turbine compressor titanium blade of zero stage: 1 - foot of disc blade locking; 2 - blade leaf; 3 - shroud plate 


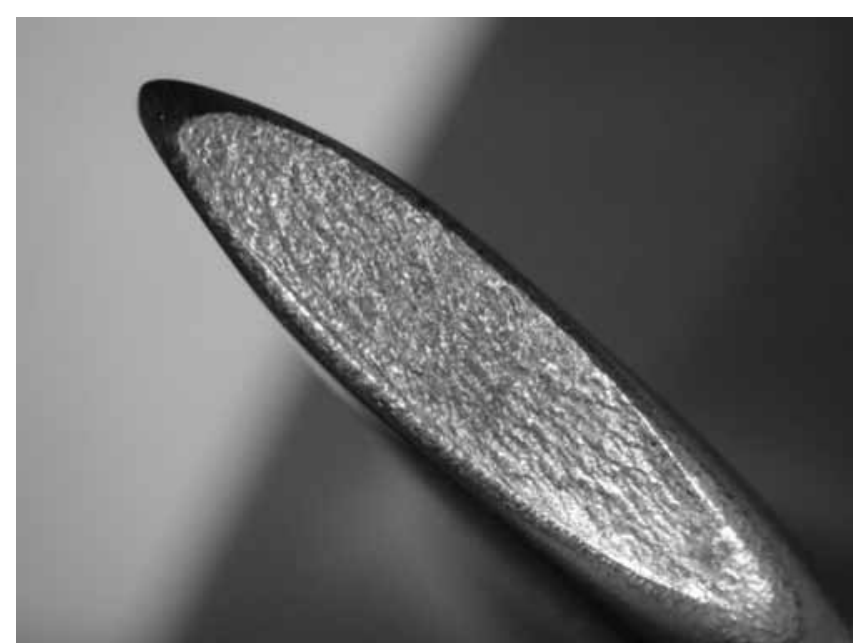

Rys. 2. Powierzchnia półki łopatki sprężarki stopnia 0 po eksploatacji. Widoczne uszkodzenia warstwy wierzchniej

Fig. 2. Surface of compressor turbine blade of 0 stage after operation. Degradation of surface layer is visible

próbuje przeciwstawić się powierzchnia stykowa półki bandaża. W efekcie występują bardzo duże siły tarcia. Dodatkowo, na skutek zmiennych sił gazodynamicznych oraz z powodu zmiennych prędkości obrotowych (gwałtownych przyśpieszeń), wspomniane miejsce narażone jest na wysokocyklowe uderzenia (młotkowanie). Łopatki sprężarki wykonane są ze stopu tytanu WT3-1 (Ti-Al-Mo-Cr) o strukturze dwufazowej $\alpha+\beta$, natomiast powierzchnia stykowa półek jest modyfikowana przez naniesienie warstw kompozytowych na osnowie niklu o grubości kilku mm, umacnianych węglikami wolframu WC i W2C, które spełniają wymagania stawiane przez warunki pracy. Pomimo to, po pewnym okresie eksploatacji, zachodzi konieczność regeneracji tych warstw (rys. 2).

Po analizie uszkodzeń warstwy wierzchniej i w wyniku przeprowadzonych badań, opracowano w Zakładzie Inżynierii Spajania Politechniki Warszawskiej metodę selektywnego napawania warstw Ni-WC w miejscach wymagających regeneracji.

\section{Stop tytanu WT3-1 - właściwości i zastosowanie}

Ze względu na swoje właściwości: wysoką wytrzymałość, odporność na korozję, zdolność nośną w temperaturze podwyższonej i kriogenicznej, odporność na pełzanie i niską gęstość, tytan i jego stopy znajdują szerokie zastosowanie w lotnictwie. Żarowytrzymały stop WT3-1 do przeróbki plastycznej opracowany został jako stop wieloskładnikowy w układzie Ti-Al-MoCr-Fe-Si. Należy do grupy martenzytycznych stopów $\alpha+\beta$ stosowanych $w$ stanie wyżarzonym jak również po obróbce cieplnej. Skład chemiczny stopu jest podany w tablicy I.

Aluminium w stopie stabilizuje i umacnia fazę $\alpha$, a także podwyższa temperaturę przemiany fazowej $\alpha \rightarrow \beta$. Molibden, stabilizując faze $\beta$, ułatwia przeróbkę plastyczną na gorąco oraz zwiększa żarowytrzymałość, szczególnie w obecności krzemu. Pierwiastki eutektoidalne stabilizujące fazę $\beta$ ( $\mathrm{Cr}$ i Fe) umacniają zarówno fazę $\beta$, jak też fazę $\alpha w$ niskiej i średniej temperaturze.

Stop WT3-1 jest stopem tytanu najczęściej stosowanym w przemyśle szczególnie na części sprężarek pracujących $6000 \mathrm{~h}$ i dłużej w temperaturze do $400^{\circ} \mathrm{C}$, a także w postaci odkuwek na części maszyn pracujące przy dużych obciążeniach. W zależności od przeznaczenia stop ten poddaje się obróbce cieplnej. Do najczęściej stosowanych należą:

- wyżarzanie izotermiczne: $870 \div 920^{\circ} \mathrm{C}$ w ciagu $1 \div 4 \mathrm{~h}$, dalej $650^{\circ} \mathrm{C}$ w ciągu $2 \mathrm{~h}$, chłodzenie w powietrzu - podstawowa obróbka części pracujących długotrwale w podwyższonej temperaturze;

- wyżarzanie dwustopniowe: $870 \div 920^{\circ} \mathrm{C} \mathrm{w}$ ciągu $1 \div 4 \mathrm{~h}$, chłodzenie $\mathrm{w}$ powietrzu, nagrzewanie, $550^{\circ} \mathrm{C}$ w ciągu $2 \div 5 \mathrm{~h}$, chłodzenie w powietrzu zwiększa stabilność cieplną i właściwości wytrzymałościowe, przy nieznacznym zmniejszeniu plastyczności;

- hartowanie i starzenie: $850 \div 870^{\circ} \mathrm{C}$ przez $1 \mathrm{~h}$, hartowanie w wodzie, dalej $400 \div 600^{\circ} \mathrm{C}$ w ciągu $1 \div 10 \mathrm{~h}$, chłodzenie w powietrzu - wzrost wytrzymałości i twardości;

- obróbka cieplno-mechaniczna: obróbka plastyczna w $550 \div 650^{\circ} \mathrm{C}$ i chłodzenie w powietrzu - dla kucia łopatek sprężarki uzyskano wzrost właściwości wytrzymałościowych o $20 \div 30 \%$.

\section{Opracowanie metody nakładania warstw Ni-WC}

Przeprowadzona analiza właściwości stopu WT3-1 wskazuje na możliwość krótkotrwałego, lokalnego nagrzewania półki bez znaczącej utraty

Tablica I. Skład chemiczny stopu tytanu WT3-1 w \% wag.

Table I. Chemical composition of WT-3-1 titanium alloy in wt. \%

\begin{tabular}{|c|c|c|c|c|c|c|c|c|c|}
\hline $\mathrm{Ti}$ & $\mathrm{Al}$ & $\mathrm{C}$ & $\mathrm{Si}$ & $\mathrm{Fe}$ & $\mathrm{N}$ & $\mathrm{O}$ & $\mathrm{H}$ & $\mathrm{Cr}$ & $\mathrm{Mo}$ \\
\hline Reszta & $5,5 \div 6,5$ & $0,10<$ & $0,2 \div 0,4$ & $0,2 \div 0,7$ & $0,05<$ & $0,15<$ & $0,012<$ & $0,8 \div 2,3$ & $2,0 \div 3,0$ \\
\hline
\end{tabular}


właściwości materiału samej łopatki, a więc na nakładanie warstwy powierzchniowej poprzez zastosowanie jednej z metod spawalniczych, wykluczając zabiegi lutowania piecowego warstw do podłoża. Możliwości sterowania energią liniową źródeł spawalniczych oraz podawania materiału dodatkowego ograniczały wybór metody. Podczas prowadzonych prób zwracano uwagę na:

- wielkość i kształt modyfikowanej powierzchni,

- dodatkową ochronę w czasie nakładania warstwy i jej chłodzenia,

- sposób podawania materiału dodatkowego,

- stopień wymieszania warstwy z podłożem,

- zmiany w SWC.

Badano procesy klasycznego napawania plazmowego (PPTAW), napawania elektrodą otuloną i napawania gazowego. Jednak niewielka powierzchnia półek (ok. $70 \mathrm{~mm}^{2}$, średnia objętość napoin $210 \mathrm{~mm}^{3}$ ) jej specyficzny, elipsoidalny kształt i zbyt szeroka SWC spowodowały eliminację wymienionych metod. Skoncentrowano się więc na metodzie napawania przy pomocy palnika mikroplazmowego (plazma-TIG).

Podczas prowadzenia prób napawania mikroplazmowego napotkano na wiele trudności technicznych i technologicznych. Dużym problemem okazał się sposób podawania materiału dodatkowego na nadtapiane podłoże, ochrona jeziorka spawalniczego i stabilność procesu z natury o niskiej energii liniowej, zakłócana dostarczaniem znacznych ilości materiału warstwy. Badano wprowadzanie go w postaci mieszaniny
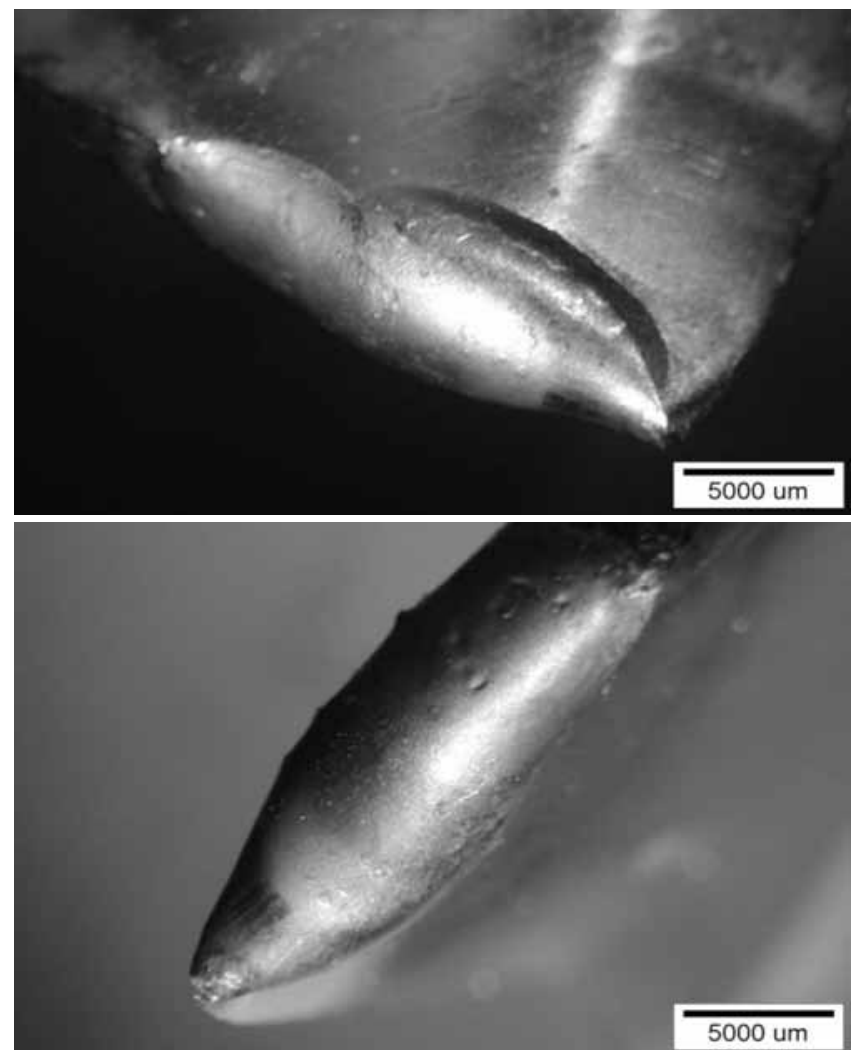

Rys. 3. „Surowe” napoiny Ni-WC na półkach łopatek turbiny przed operacją szlifowania

Fig. 3. Raw Ni-WC layers over turbine blade plates prior to grinding proszków stopu Ni i węglika WC z podajnika, nakładania na podłoże specjalnej pasty z następującym jej przetapianiem, natapiania kompozytowego pręta Ni-WC uprzednio wykonanego w piecu próżniowym. Badano możliwości procesu w szerokim zakresie parametrów technologicznych, w tym ciągłego i impulsowego prądu napawania.

Udało się osiągnąć zadowalające i powtarzalne wyniki. Wykonano specjalne oprzyrządowanie w postaci komory argonowej i uchwytu-przyrządu mocującego, chłodzonego wodą, z dodatkowym nadmuchem. Metoda umożliwia uzyskiwanie odpowiedniego rozkładu ciepła, właściwe formowanie kształtu napoiny, zachowanie struktury kompozytowej z równomiernym rozkładem fazy umacniającej, ochronę materiału łopatki przed nadmiernym nagrzewaniem, a także możliwość sterowania parametrami procesu w wygodnym „oknie technologicznym", w tym dla prądu napawania w za-

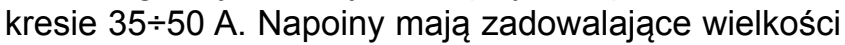
naddatków na krawędziach przewidzianych na obróbkę mechaniczną. Przykładowe elementy pokazano na rysunku 3 .

\section{Badania warstw napawanych}

$\mathrm{Na}$ rysunku 4 przedstawiono strukturę warstw Ni-WC. Rysunki przedstawiają kompozytowy charakter napoin. Widoczne są duże, nieregularne cząstki
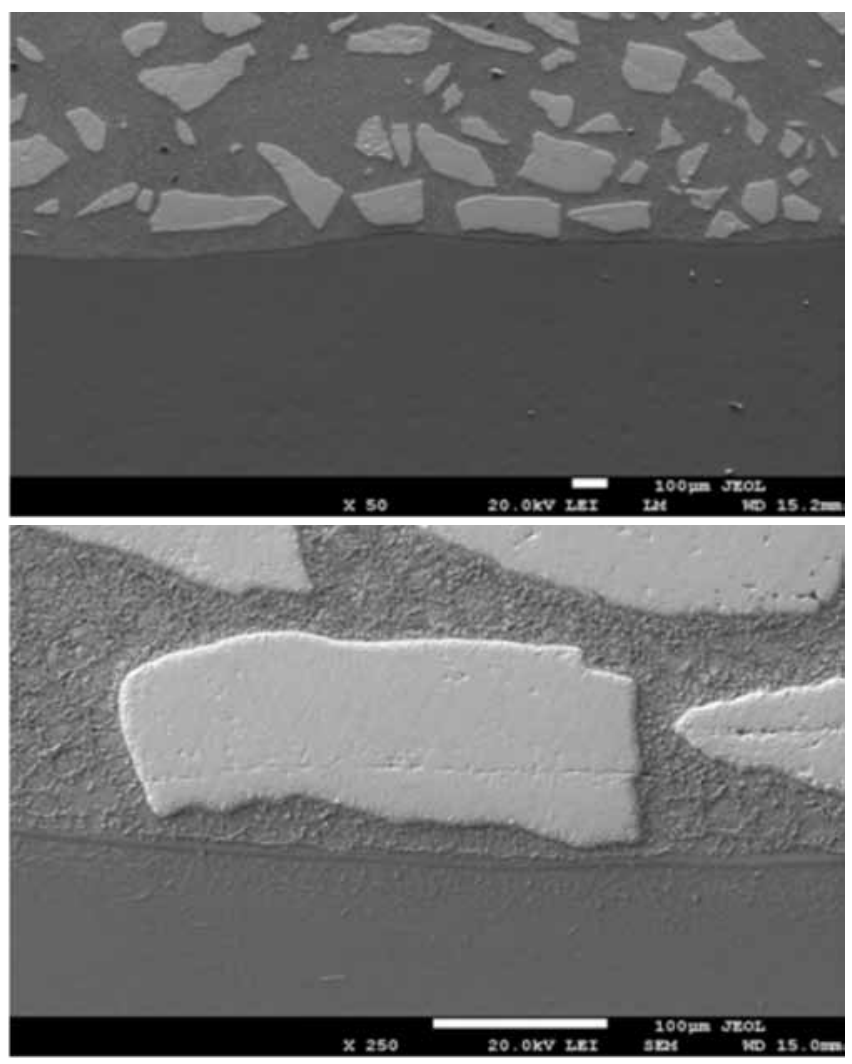

Rys. 4. Struktura kompozytowa warstw napawanych, dobre połączenie z podłożem

Fig. 4. Composite structure of overlays. Correct joint with the substrate 


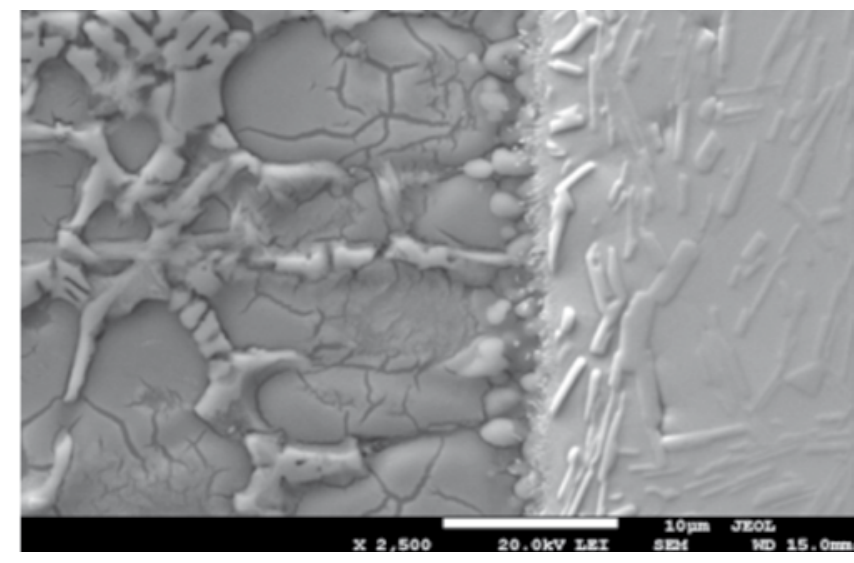

Rys. 5. Granica międzyfazowa węglik WC (z prawej)-osnowa Ni Fig. 5. WC carbide (right)-Ni matrix interface

węglika na tle osnowy niklowej. Granica pomiędzy warstwą i podłożem jest ciągła, bez niezgodności spawalniczych.

Kluczowym zagadnieniem w przypadku materiałów kompozytowych jest adhezja pomiędzy cząstkami umacniającymi i osnową warstwy. Na rysunku 5 przedstawiono okolice granicy pomiędzy tymi fazami przy

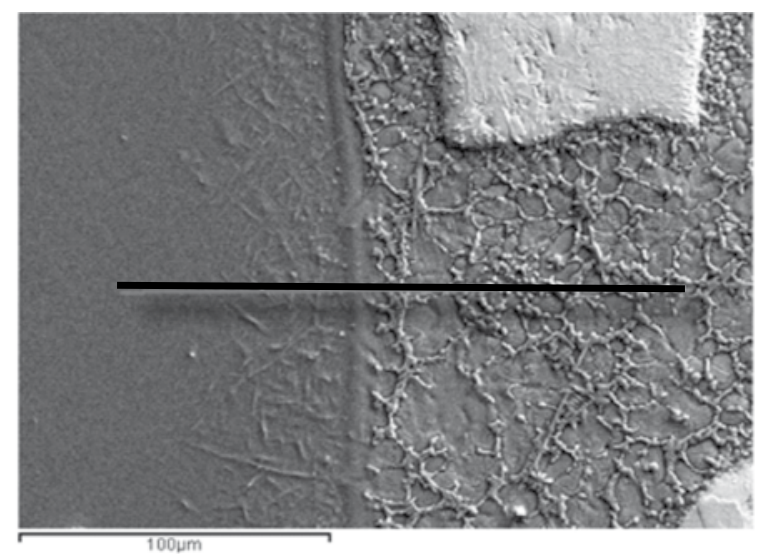

$\mathrm{Al}$

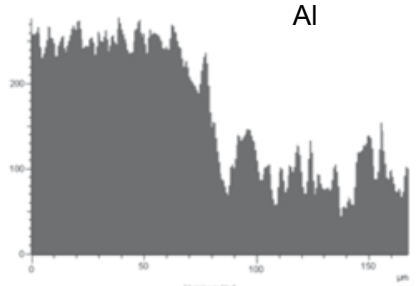

$\mathrm{Ti}$

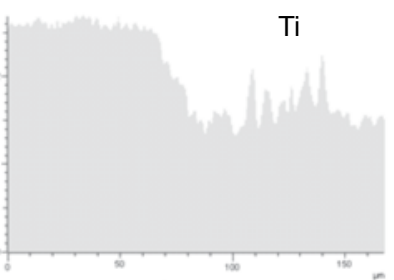

$\mathrm{Ni}$
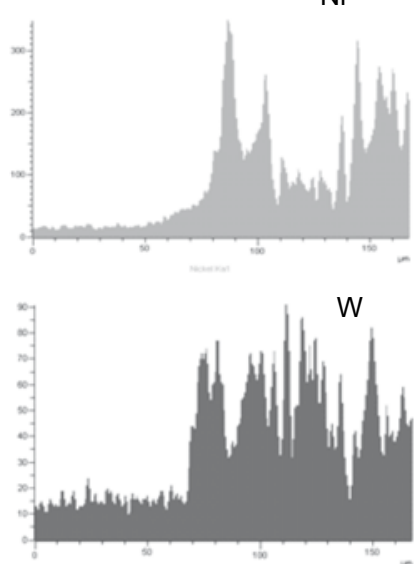

Rys. 6. Granica napoina - podłoże: struktura i rozkład podstawowych pierwiastków wzdłuż zaznaczonej, prostopadłej do niej linii analizy

Fig. 6. Overlay - substrate boundary: structure and distribution of main elements along the perpendicular to it marked line of analysis dużym powiększeniu. Granica jest ciągła, widoczna jest wąska strefa przejściowa. Osnowa warstwy ma budowę dwufazową. Po drugiej stronie granicy, po stronie węglika, widoczne są drobne wydzielenia. Rysunek dokumentuje skomplikowaną budowę złącza, jednak charakter granicy węglik-osnowa nie budzi wątpliwości z punktu widzenia jej ciągłości i zdolności do przekazywania obciążeń.

Podjęto próbę dokładniejszej charakterystyki granic warstwa-podłoże i węglik wolframu-osnowa warstwy, dla określenia charakteru oddziaływania faz stałych (podłoża i cząstek węglika) z cieczą-osnową niklową rozcieńczaną nadtapianym podłożem tytanowym w trakcie procesu napawania. W tym celu wykonano analizę struktury z wykorzystaniem polowego emisyjnego mikroskopu skaningowego wyposażonego w spektrometr z dyspersją długości fali (WDS). Wykonano analizę ilościową punktową, liniową oraz jakościową powierzchniową stężeń powierzchniowych, wzdłuż linii analizy pierwiastków: $\mathrm{Ni}, \mathrm{W}, \mathrm{Ti}, \mathrm{Al}, \mathrm{O}, \mathrm{Cu}, \mathrm{C}$. Badania przeprowadzono dla obszaru podłoże-linia wtopienia-nałożona warstwa kompozytowa, oraz z obszaru osnowa-pojedyncza cząstka węglika wolframu. Wybrane wyniki analizy pokazano na rysunku 6 i 7.
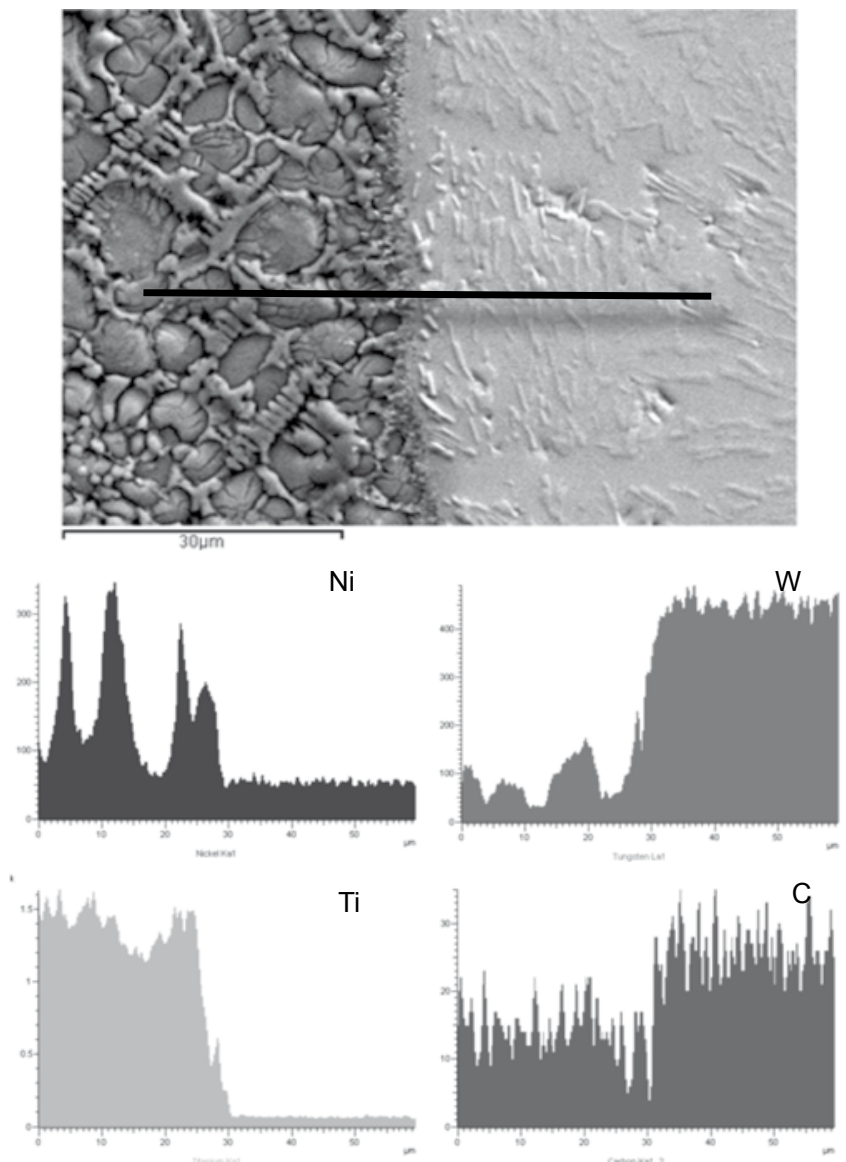

Rys. 7. Okolice granicy międzyfazowej węglik wolframu-osnowa warstwy i rozkłady liniowe wybranych pierwiastków wzdłuż zaznaczonej linii analizy

Fig. 7. Area close to the tungsten carbide-matrix of layer boundary and linear distributions of selected elements along the marked line of analysis 
Na rysunku 6 widoczne jest liniowy rozkład stężenia podstawowych pierwiastków wzdłuż zaznaczonej linii analizy, prostopadle do granicy warstwa - podłoże. Na samej granicy wyróżnić można wąską strefę pośrednią. Jest ona zbudowana z tytanu, niklu i wolframu. Wszystkie te pierwiastki mają silne powinowactwo metalurgiczne do siebie, o czym świadczy fakt, iż ich diagramy równowagi fazowej zawierają roztwory stałe i fazy międzymetaliczne, a także wysokie wartości ich ciepła tworzenia. Podłoże ze stopu WT3-1 ulega modyfikacji w strefie przyległej do granicy z nałożoną warstwą, gdzie widoczny jest wyraźny rozrost ziarna na grubości do ok. $200 \mu \mathrm{m}$. Pojawiają się tam także fazy Ti-Al. Al w stopie wyjściowym znajduje się w roztworze, ale pod wpływem ciepła procesu, w pobliżu linii wtopienia zachodzi wykrystalizowanie wspomnianych wyżej faz. Jest to termodynamicznie uzasadnione, gdyż energie swobodne ich tworzenia są wysokie. Osnowa napoiny przyległa do linii wtopienia ma złożony skład chemiczny i strukturalny. Jest wyraźnie wzbogacona w Ti oraz Al (składniki podłoża), w roztworze stałym zawiera także wolfram. Świadczy to niewątpliwie, iż w trakcie napawania podłoże jest nadtapiane i jego składniki ulegają wymieszaniu z ciekłą osnową na bazie niklu. Dochodzi również do destrukcji cząstek węglika drogą intensywnego rozpuszczania się w cieczy, przy czym zarówno wolfram jak i węgiel przechodzą do roztworu.
Drugim interesującym obszarem są okolice granicy międzyfazowej węglik wolframu - osnowa warstwy. Przedstawiona wcześniej granica warstwa podłoże miała charakter makroskopowy i tworzyła się wskutek nadtapiania tego ostatniego i mieszania się ciekłego stopu tytanu ze stopem niklu, natomiast granice pomiędzy węglikiem i osnową są płaszczyznami oddziaływania zakrzywionych cząstek fazy umacniającej kompozytu o wymiarach dziesiątków mikrometrów z otaczającą te cząstki cieczą na osnowie niklu. Na rysunku 7 pokazano strukturę takiej granicy i rozkłady liniowe najważniejszych pierwiastków. Profil stężenia wolframu wskazuje na destrukcję i rozpuszczanie się węglika w cieczy. W warstwie przejściowej sytuuje się ponadto tytan z podłoża, który jest powierzchniowo aktywny na tej granicy. Drobne wydzielenia blisko granicy, wewnątrz cząstek WC, są kryształkami węglika chromu, który w warunkach procesu dyfunduje przez granicę z ciekłego roztworu, wypierając wolfram ze związku z węglem. Jest to zrozumiałe, biorąc pod uwagę jego znacznie wyższe powinowacwo chemiczne do tego pierwiastka. Charakter granicy wskazuje na skomplikowane, intensywne oddziaływanie międzyfazowe w wieloskładnikowym układzie.

\section{Wnioski}

Opracowano metodę regeneracji kompozytowej warstwy wierzchniej Ni - WC tytanowych półek łopatek turbiny silnika odrzutowego przy zastosowaniu napawania mikroplazmowego.
Wyniki badań strukturalnych i rozkładu pierwiastków okolicy linii wtopienia warstwy kompozytowej w podłoże oraz granicy międzyfazowej osnowa warstwy -węglik wolframu wskazują na intensywne oddziaływanie cieczy z fazą stałą podczas procesu napawania.

\section{Międzynarodowa Konferencja Naukowo-Techniczna \\ NAPAWANIE - POSTĘP I ZASTOSOWANIA \\ Wroclaw, 19-21 wrzesień 2011}

\section{Sesja Posterowa}

\begin{tabular}{|c|c|c|}
\hline \multicolumn{3}{|c|}{ Wtorek, 20.09.2011 } \\
\hline Godzina & Autorzy & Tytuł \\
\hline $\begin{array}{c}\text { Sesja } \\
\text { Posterowa }\end{array}$ & \multicolumn{2}{|c|}{ Przewodniczący: prof. dr hab. inż. dr hab. inż. Zbigniew Mirski, prof. PWr prof. D.Sc. (Tech) Valerii Kuznetsov } \\
\hline \multirow{4}{*}{$12^{30}$} & Dr inż. Tomasz Szulc, Politechnika Wrocławska & Początki napawania. Pierwsze metody i zastosowania \\
\hline & $\begin{array}{l}\text { Prof. Dr.-Ing. habil. Johannes Wilden } \\
\text { Hochschule Niederheim, Niemcy }\end{array}$ & $\begin{array}{l}\text { Auftragschweißen von nanokristallin erstarrenden } \\
\text { Eisenbasiswerkstoffen auf Aluminiumsubstraten } \\
\text { (Napawanie nanostrukturalnie krystalizujących materiałów } \\
\text { na osnowie żelaza na podłoże aluminium) }\end{array}$ \\
\hline & $\begin{array}{l}\text { Dr inż. Piotr Białucki, Dr inż. Wiesław Derlukiewicz } \\
\text { Politechnika Wrocławska }\end{array}$ & $\begin{array}{l}\text { Napawanie w regeneracji kokili do odlewania } \\
\text { ciśnieniowego aluminium }\end{array}$ \\
\hline & $\begin{array}{l}\text { Dr inż. Marek Gucwa, Dr Inż. Robert Bęczkowski } \\
\text { Politechnika Częstochowska }\end{array}$ & $\begin{array}{l}\text { Odporność na zużywanie erozyjne napoin } \\
\text { przy kącie padania ścierniwa wynoszącym } 60^{\circ}\end{array}$ \\
\hline \multicolumn{3}{|c|}{ ZWIEDZANIE WYSTAWY oraz LABORATORIUM WYTWARZANIA PROSZKÓW (bud. B9, pok. 115) } \\
\hline $13^{00}$ & \multicolumn{2}{|c|}{ PRZERWA NA OBIAD } \\
\hline
\end{tabular}

Program sesji III w numerze 10/2011 na stronie 3 